Conversely, x-ray treatment is inadrisable only when an imminent danger, a pedicle twist, an acute hemorrhage or sepsis demands an immediate operation.

Compared to radium, the x-rays have a wide range of applicability. The latter may be employed even in the presence of salpingitis where radium is strictly contraindicated. X-ray treatments, finally, are available everywhere, whereas radium is in the hands of only a privileged few.

George Gellitorn.

\title{
Gellhorn: When to Operate and When to Use Radium on Fibroids of the Uterus.
}

Journal American Medical Association, 1922, 1xxviii, 259.

Gellhorn feels that the principal field for radium is in women over 40 who have fibroids not extending to the umbilicus. It is further indieated in those who are, for some reason, poor operative risks and those who object to any form of operation.

Aceording to the statistics of Gauss and Friedrich, the hemorrhage is controlled in 98.4 per cent and there is more or less shrinkage of the tumor in 70 to 80 per cent of the eascs radiated. Gellhorn believes that the rays have a direct destructive action on the tumor cells, as mere castration would not cause the rapid shrinkage observed in some cases.

All tumors extending above the umbilicus and all large pedunculated subserous and submucous fibroids should be operated on, as well as all cervical fibroids. Suppurating, necrotic and gangrenous fibroids are unsuitable for radiation, as well as those undergoing cystic or calcareous degeneration. Co-existing adnexal disease is an indication for surgery. Gellhorn feels that radiotherapy is justified in cases of sareomatous degeneration, provided the dose is correspondingly large.

The success in the use of radium depends upon the proper selection of eases. Gellhorn prefers radium to x-rays, but oecasionally uses the two in combination. Ordinarily he employs $1200 \mathrm{mg}$. hours within the uterine cavity. This treatment he administers preferably after the menstrual, period. While calling attention to the absence of any operative mortality, which is from 3 to 5 per cent, he admits that he has found it applicable in only about 60 per cent of the cases coming under his care.

R. E. WobUs.

\section{Taussig: In What Cases Do Uterine Fibroids Still Require Operative Removal?} Journal American Medical Association, 1921, lxxvii, 357.

Taussig prefers radium to $x$-rays in the treatment of uterine fibroids and believes that it will eventually replace operation in most cases. However, he realizes certain very definite contraindications to its use. Among these are the following: sizo. Tumors more than $12 \mathrm{~cm}$. in diameter should be removed by the knife. Location. Submueous fibroids protruding through the eervix, subserous fibroids with pediele, cervical fibroids and intraligamentous fibroids should be operated on. $D e$ generation. Rapidly growing tumors, ealcified or necrotic fibroids and those complicated by malignancy are unsuitable to radiation. Age. Not age, but the desire for children and the preservation of menstruation, are indications for myomectomy or hysterectomy. Complications. Pyosalpynx and ovarian cysts make operation imperative.

R. E. Wobus.

Wiener: The Present Status of the Treatment of Uterine Fibroids. New York Medical Journal, 1921, exiv, 400.

The author presents his conclusions as follows: 1. Many fibroids require no treatment whatsoever. 2. Radiotherapy is a more radical method of treatment than operation because it destroys the ovary. 3. The contraindications to radiotherapy 